\title{
Bridging and academic support for first year university students: preparation of the lecturing staff
}

\section{H.L. Botha and C.D. Cilliers}

Every man is born with a live computer of limitless possibilities, but without the instruction manual. The most important job of science today is to draw up that manual (Machado 1980:26).

Academically disadvantaged students encounter many problems in coping with a medium of instruction other than their own mother tongue at tertiary level. The authors established additional needs, e.g. the upgrading of thinking and study skills, which were, in the programme under discussion, addressed simultaneously with the language component. They outline the plan, structure and implementation of a project consisting of a seven-week bridging course and an academic support programme lasting a full academic year. A blueprint for an Academic Preparational and Support Programme is discussed. Conclusions and recommendations follow.

Studente met akademiese agterstande ondervind baie probleme op tersiêre vlak met die onderrigmedium wat nie hul moedertaal is nie. Die skrywers het addisionele behoeftes bepaal, soos die opgradering van denk- en studievaardighede, wat saam met die taal aandag geniet het in die program onder bespreking. Hulle verstrek die plan, struktuur en implementering van 'n projek wat bestaan uit 'n sewe-week brugkursus en 'n akademiese ondersteuningsprogram vir die duur van 'n volle akademiese jaar. 'n Meesterplan vir 'n Akademiese Voorbereidings- en Ondersteuningsprogram word bespreek. Gevolgtrekkings en aanbevelings sluit die artikel af.

\section{INTRODUCTION}

In a rapidly changing South Africa the focus is shifting more and more to the educational scene. The political issues in education get their fair share of attention, but the practical implications of many of these changes have not yet been fully understood or comprehensively addressed. More institutions are being confronted with situations not anticipated before. It is imperative that these challenges should be approached scientifically with the aim of finding the most effective ways to help educationally disadvantaged students. Lessons should be learnt from personal experience, but also from those who have been in similar positions for a number of years (cf. Hofmeyr and Spence 1989; Mehl 1988; Sass 1988; Tema 1988; and Schochet 1986). 


\section{TARGET POPULATION AND THEIR NEEDS}

Institutions which traditionally catered for only one population group are becoming increasingly more integrated. The University of Stellenbosch is such an institution, with substantially more students from other population groups enrolling every year. Many of these students come from a scholastic environment which one can only describe as dismally inadequate. The reasons for the inadequate schooling will not be discussed here, but language proficiency is often the area in which the greatest deficiency is concentrated (Puhl and Swartz 1989:21-22). Students who received their schooling through medium of a second (sometimes even a third or fourth) language, find it extremely difficult to cope in a tertiary environment where the medium of instruction is also their second (third or fourth) language. The fact that the medium of instruction is the majority of the other students' mother tongue accentuates the problem.

Language proficiency and cognitive ability are inseparably interwoven and interdependent (Nickerson et al. 1985). It is therefore understandable that students with language backlogs will also experience difficulty with the comprehension of concepts and other higher order operations. Upgrading language proficiency alone is thus not sufficient; thinking ability or thinking skills (including concept formation) should also receive additional attention in order to address some of the most crucial needs of these students.

A project was conducted at the University of Stellenbosch in 1990/91 with a group of students who fall into this category. The project consisted of a bridging course lasting seven weeks at the end of 1990, followed by an ASP (academic support programme) conducted at the university throughout the 1991 academic year. In addition to the needs mentioned above, these students also needed assistance in the following areas to help them adapt, grow personally, and progress academically:

* $\quad$ intra-personal skills (including self acceptance, motivation, etc.)

* inter-personal skills (including skills to cope in a cross-cultural environment)

* the development of dispositions to thrive and benefit optimally in a stimulating, multi-cultural environment.

The needs of such disadvantaged students are highly complex and diverse, therefore a multi-disciplinary approach was adopted in the University of Stellenbosch project, which will be discussed in some detail in the ensuing sections.

\section{PLANNING THE BRIDGING COURSE}

The course was scheduled to take place just before the students embarked on their first year of university study. The main objectives of the 1990 seven-week course (in preparation for the 1991 academic year) were:

* upgrading language proficiency necessary to cope with the linguistic demands of the university

* equipping the student with thinking skills which would assist him/her to use his/her cognitive ability more effectively in the university environment

* improving affective variables.

The course also touched upon the following secondary components:

* $\quad$ self-concept and motivation (inner locus of control)

* $\quad$ study methods 
* logical reasoning as an aid to understanding and writing about subject content

* oral expression.

This was an intensive course intended to bridge the most serious gaps between school and university regarding language and thinking skills. The aim of the course was to improve significantly the chances of the target students completing their first year of study successfully.

Empirical work, done in the last three years at the University of Stellenbosch in the field of intensive bridging, has indicated the success of these courses (Puhl and Swartz 1989; Puhl 1990 1991). Measuring instruments used in the research as pre- and post-tests revealed that significant improvements were registered by these students in the fields of language proficiency, thinking skills and self-concept. Although many variables played a role, the pass rate from 1989 to 1990 improved significantly, probably as a result of the changes made to the content of the course (Puhl 1991). A crucial factor, which was beyond the control of the Stellenbosch researchers in the case of the two previous bridging courses, was the ASP at the various universities where these students studied. The 1990/1991 project differed from previous projects, as, for the first time, lecturing staff at the faculty of study and researchers responsible for the bridging course cooperated closely in planning and structuring the ASP which followed.

\section{WORKSHOP WITH LECTURING STAFF TO DESIGN AN ASP}

In order to design an appropriate ASP to address the specific needs of the target students, the researchers held a workshop, lasting one week, with the lecturing staff at the faculty of study. At this workshop, the staff were informed of the content covered and skills developed during the intensive bridging course. There was also an opportunity to discuss and analyse the academic situation at the faculty where the students were to study. Thereafter researchers and staff worked together to design and develop an ASP making provision for the specific demands of the faculty, and the identified needs of the target students, as a means of extending and supplementing the work done in the bridging course.

The goal was that the ASP should be the product of the lecturing staff, with two facilitators providing the link with the bridging programme. Although the ASP is referred to as a product, it is in fact a continuous process of providing academic support - a process which is continually evaluated and adapted.

The main thrust of the workshop is outlined below.

\subsection{Provision of a big picture}

1 The lecturing staff were briefed on the nature and content of the bridging course of seven weeks.

2 The emphasis which was placed on language and thinking skills was explained - especially the role of language across curricula, and the necessity for the integration of thinking skills with other subjects.

3 The role of the lecturing staff in the design of the ASP was then negotiated, and a tentative plan of action was worked out together. A specific attempt was made to convince the lecturing staff that they were all part of the team, and that success would only be possible if the staff of the bridging/support programmes co-operated optimally. 


\subsection{The role of language (communication)}

1 The needs analysis, which was done before the bridging course commenced, was discussed. The researchers explained how the presenters of the bridging course had attempted to make provision for the language needs.

2 Procedures that could be used to sustain and extend language assistance as part of the ASP were then discussed in detail. The possibility of using special lecturers in fixed slots for this purpose was thoroughly debated.

3 The role of the individual subject lecturer in this respect was also discussed. Special mention was made of the subject specific terminology, and the use of English instead of Afrikaans (the University of Stellenbosch is an Afrikaans medium institution).

\subsection{The role of thinking skills}

1 A short overview of the history and theory of the teaching of thinking was provided.

2 The thinking instruments covered with the target students during the bridging course were discussed and some of the most important ones were demonstrated, applied and practised, e.g. tools from CoRT Thinking (De Bono 1986), and instruments from Odyssey: A curriculum for thinking (Adams 1986).

3 The integration of thinking skills with the different subjects was discussed and then applied in the various disciplines. The emphasis was on transfer, which is an important aim in the teaching of thinking, especially in languages (Swartz 1991:47). This exercise was done with the aid of an integration model developed by Perkins (1989) (see Figure 1 on next page). Working in small groups, the subject lecturers investigated ways in which the thinking tools could be applied to their various fields.

The purpose of this integration model is to guide the subject lecturer in the planning of his/her original lesson to think of the most important aspects the students need to understand. The next step is to decide whether or not to build objectives for thinking into the same lesson to enhance comprehension and internalization of the subject matter. In other words: In what way can the lecturer involve the student more intelligently in the lesson? Then the lecturer should revise the lesson plan, bringing in specific tools (or strategies) to ensure that good thinking will be part of his/her lesson. The final step is to consider future lessons, and how the thinking tools can be optimally used to enhance overall comprehension or insight.

\subsection{Psychological factors}

1 The latest research on the brain and the didactic implications thereof were discussed, and a psychological perspective of the learner was provided. The implications of this information were addressed in the context of an ASP, e.g. the fact that the most recent brain research clearly indicates that optimal learning can only take place when the student is stimulated in such a way that the simultaneous integration of the brain systems occurs (Du Preez 1991).

2 Another topic covered was mental health and coping with stress. This was done to enable the lecturing staff to recognize and deal with students who may be suffering from excessive stress as a result of academic pressures. 
FIGURE 1

INTEGRATION OF THINKING TOOLS INTO ACADEMIC SUBJECTS

\section{TRANSFER MODEL}

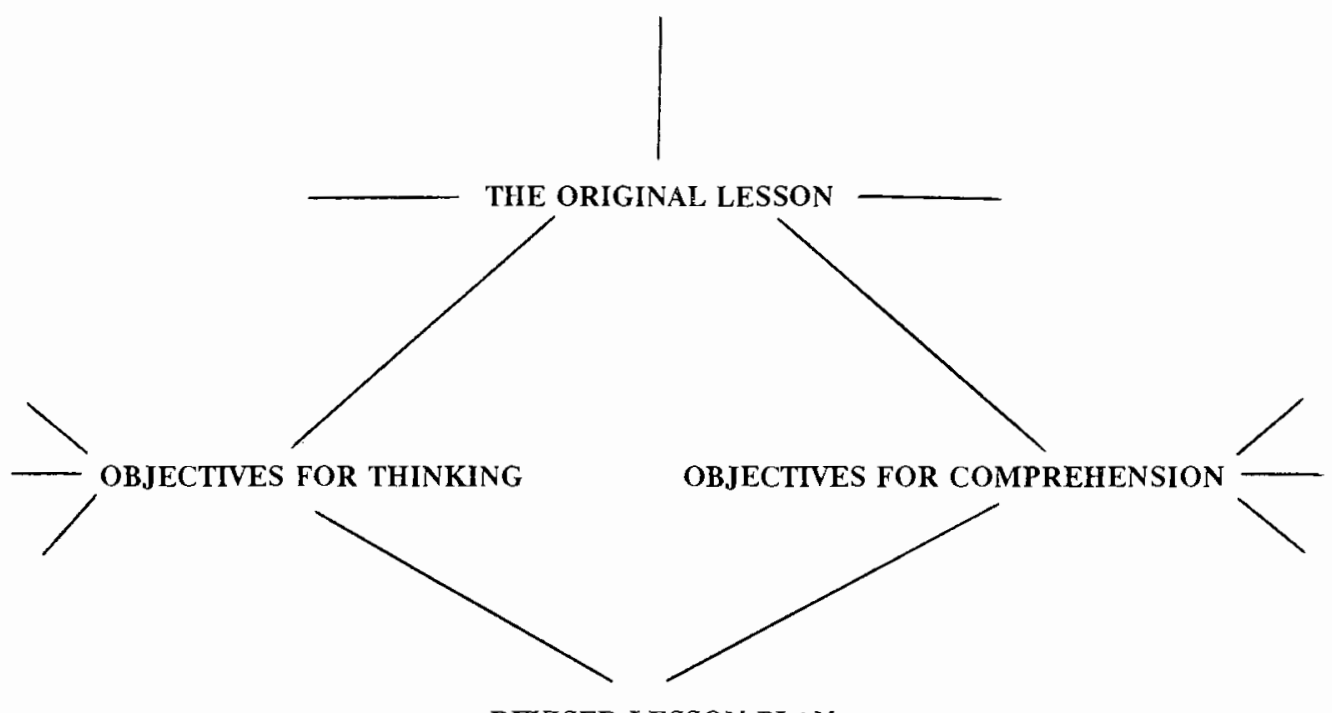

REVISED LESSON PLAN

FURTHER ASPIRATIONS

FOR THINKING

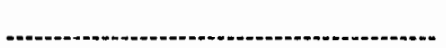

FOR COMPREHENSION 
3 Student motivation was an important topic and the lecturing staff were invited to make contributions in this regard. Specific strategies that could be used to encourage motivation in the context of the various subjects at the faculty were suggested, e.g. using the channels of the ASP to take a personal interest in particular students.

\subsection{Structure of the ASP}

In negotiating and structuring the ASP, the following aspects received attention:

1 The compatability of the bridging course with the ASP was discussed. Special attention was given to how work done in the bridging course could be followed up during the ASP.

2 The role of subject-directed support and ways of achieving it, were thoroughly discussed.

3 The use of practical periods for group work as part of the ASP, as well as the involvement of the relevant staff in these practical periods, was discussed.

4 A psychological profile of the target students was provided in the context of; inter alia, guiding and orientating them to study more effectively, and to grow as people. The use of available student guidance counsellors, courses on study methods available on video, and linking up with the work done during the bridging course in this respect, were all considered important elements of the ASP.

5 An aspect which was raised by the lecturing staff during the workshop was the involvement of peer facilitators. Peer facilitators could be used to assist in mainly the subject specific fields of academic support. If used this system must be closely monitored by the subject lecturers as well as the ASP co-ordinators, because students cannot be expected to facilitate optimally without specific guidelines. At least three models are possible: viz using competent students as faciltators for students in the same year group; using competent senior students, or using competent students from both these groups. University personnel reluctant to use such a peer faciltator programme often ignore its three-fold benefit of:

* the obvious advantage for the students needing academic suppport

* the possibility of the peer faciltator growing academically by extending and monitoring his own skills, depth of comprehension and knowledge, and increasing his/her self-confidence

* the advantage to the ASP staff of sharing the responsibility for the academic support.

6 With the aim of refining, improving and extending the ASP, ways and means of evaluating the programme most effectively, were carefully considered.

\subsection{Outline of the designed ASP}

During the workshop the lecturing staff of the faculty drew up a blueprint of an Academic Preparational and Support Programme (APSP) which contained the following main categories:

1 Objectives

2 Functions

3 Management 
Academic Selection Programme

Academic Preparation Programme (i.e. bridging course)

Academic Support Programme, containing the following sub-categories:

- $\quad$ orientation of the target students

- duration of ASP

- scheduling the ASP

- tasks of the faculty council, the co-ordinating team, the subject lecturers, and other support services, like student counsellors

- programme evaluation.

During the workshop it became even more apparent that a distinction should be drawn between the intensive bridging course and the ASP which followed it. The ASP should be designed to build on the foundation which had been established during the bridging course, and should run during the first (and even second and third) year of academic study. The ASP should further be designed to provide additional support to the students in the areas where the needs are the greatest, e.g. in communication skills, study methods, and specific subject areas.

The feedback obtained at the end of the week showed that the majority of the participants (more than $90 \%$ ) considered that the workshop had achieved its aims of designing an ASP, and preparing for its implementation.

\section{CONCLUSIONS AND FINAL RECOMMENDATIONS}

The notion of bridging/support programmes is clearly a highly complex one. In view of the bridging/support programme presented at the University of Stellenbosch, the following can be concluded:

* The positive feedback from the bridging course students and the meaningful improvements registered after extensive testing are evidence of their initial acceptance of the concept of bridging/academic support.

* Post-test results and subsequent monitoring of student achievements indicate a positive prognosis for this bridging/support programme.

* Complete co-operation amongst all the parties involved in this bridging/support programme was a crucial component. It was, however, extremely difficult to achieve.

* The success of the bridging/support programme was inhibited by the unwillingness of some of the lecturing staff to accept responsibility for providing additional assistance to the target students in specific subject fields.

* Despite the reservations some staff had, it was possible to make adjustments to assist disadvantaged students. Regarding academic standards, the following analogy captures the essence of the approach adopted: It is not necessary or advisable to lower the height of the high jump cross bar, but the run-up of the high jumper should be extended and improved.

* One of the objectives of the bridging course was to address poor self-image, which often gives rise to lack of self-confidence, low self-expectations, and, more often than not, poor inter-personal relations and academic results. By the use of various techniques and confidence building strategies, these problems were addressed during the bridging course. Unfortunately, students at an academic bridging course (and also those qualifying for an ASP) are often perceived as poor students with 
limited potential. This is a view shared by lecturers and students alike. All lecturers involved in the bridging/support programme should guard against displaying this attitude and should rather encourage students to see themselves and their potential in a more positive light.

* Many of the problems students face are not immediately apparent. This emphasizes the need to involve a multi-disciplinary team to address the many complex and often covert student needs.

The following recommendations can be made:

* From the first stages of planning such a programme, all the staff participants should be involved to ensure stakeholdership.

* Follow-up visits revealed the existence of certain additional needs. Especially subjects like Mathematics and Physical Science, where applicable, require specialist attention.

* An important function of the ASP should be to provide regular feedback to all lecturing staff involved with first year bridging/support students. The feedback should include directives regarding didactic adaptations, as well as the extent and nature of additional individual support. It should cater for the total student, and take the total learning environment into consideration (Clark 1986). This includes physical, emotional, cognitive, volitional, and social needs. Feedback should also be given to the students to ensure that they are aware of their progress (or lack of it), and the problem areas they experience. (Whether the ASP under discussion managed to fulfil these expectations, will be reported at the beginning of 1992.)

* Although these areas received some attention in 1990/91, more attention should be given in future bridging/support programmes to the development of intra- and interpersonal skills (e.g. inner locus of control, handling cultural differences in a multi-cultural environment, etc.). This recommendation obviously implies the extension of the multi-disciplinary team responsible for the bridging/support programme.

* Students with specific needs which require specialist intervention should immediately be referred to those specialists (e.g. student counsellors, reading experts, psychologists, etc.) who are equipped to assist them, and who form a vital extension of the ASP team. The recommendations of these specialists must then be deliberately and consistently followed up. These specialists could also be drawn in as advisors (consultants) by the ASP staff, emphasizing the notion that the ASP programme should be flexible, open, and multi-disciplinary in its approach.

* Further research in this field is imperative, and the following aspects could be considered:

- $\quad$ selection procedures, especially to ensure that more homogeneous groups are formed for the bridging course

- $\quad$ experimentation with various models of a bridging/support programme (e.g. a year of bridging, followed by ASP the next year; a couple of weeks of bridging followed by ASP during the first year; an ASP without any bridging)

- $\quad$ experimentation with various contents to determine the optimal input required to address the most critical needs of the target students in both the bridging course and the ASP (e.g. the type of language and thinking skills required by these students)

- longitudinal studies to monitor the progress (or lack of progress) of target students throughout their academic careers 
ways of establishing the effects of different types of subject lecturer support during the ASP.

It has become clear during 1991 that most of the target students are capable of achieving success. However, these students cannot be expected to assume full responsibility for their academic progress. They become the special responsibility of the lecturers who should guide them towards developing and using their latent potential to ensure academic success. Only then can a bridging/support programme help draw up the instruction manual which Machado (1980) regarded as essential to enable man to use his limitless possibilities.

\section{REFERENCES}

ADAMS, M.J. (Curriculum Coordinator) 1986. Odyssey. A curriculum for thinking. Watertown, Ma: Mastery Education Corporation.

CLARK, B. 1986. Optimizing learning. The integrative education model in the classroom. Columbus: Merrill Publishing Co.

DE BONO, E. 1986. CoRT thinking. New York: Pergamon Press

DU PREEZ, J.J. 1991. Neurokognitiewe integrasie en die leerproses. Per Linguam, Vol. 7, No. 1, 25-37.

HOFMEYR, J. AND R. SPENCE. 1989. Bridges to the future. Optima (Anglo American House Joumal), Vol. 37, No. 1, 37-48.

MACHADO, L.A. 1980. Translated by Mark C. Wheeler. The right to be intelligent. Oxford: Pergamon Press.

MEHL, M.C. 1988. Academic support: Developmental giant or academic pauper? South African Journal of Higher Education, Vol. 2, No. 1, 17-20.

NICKERSON, R.S.; D.N. PERKINS and E.E. SMITH. 1985. The teaching of thinking. Hillsdale, New Jersey: Lawrence Erlbaum Associates.

PERKINS, D.N. 1989. A model for the integration of thinking skills. Unpublished document prepared for a seminar at the Institute for Language Teaching, University of Stellenbosch.

PUHL, C.A. 1990. The challenge of bridging. Description and results of a short-term intensive bridging course in English and thinking skills in January 1989 at ESKOM College: Final project report. Unpublished report prepared for ESKOM. Stellenbosch: Institute for Language Teaching, University of Stellenbosch for the UPTTRAIL Trust.

PUHL, C.A. 1991. Bridge to the future: Final report on 1990 bridging course at ESKOM College. Unpublished report. Stellenbosch: Institute for Language Teaching, University of Stellenbosch for the UPTTRAIL Trust.

PUHL, C. A. and J. J. SWARTZ. 1989. Designing a second language bridging course for university students. Per Linguam, Vol. 5, No. 1, 17-32.

SASS, A. 1988. Academic support in engineering at the University of Cape Town. South African Journal of Higher Education, Vol. 2, No. 1, 25-28. 
SCHOCHET, I. 1986. Manifest and potential performance in advantaged and disadvantaged students. Unpublished Ph.D. dissertation, University of the Witwatersrand.

SWARTZ, J.J. 1991. Thinking skills and communicative language teaching: a curriculum perspective. Per Linguam, Vol. 7, No. 1, 39-47.

TEMA, B.O. 1988. Academic support: Its assumptions and implications. South African Journal of Higher Education, Vol. 2, No. 1, 29-31. 